\title{
HORASAN TÜRKÇESINIIN BOCNURD AĞZINDA KANITSALLIK (EVIDENTIALITY)
}

\section{EVIDENTIALITY IN BOJNURD DIALECT OF KHORASAN TURKIC}

\author{
Talip DOĞAN*
}

\begin{abstract}
$\ddot{O} z$
Kanıtsallık (evidentiality), olayla ilgili bilginin hangi kaynaklardan elde edildiğini bildiren bir dil bilgisi kategorisidir. Türkçede kanıtsallık, bilginin dolaylı yollardan sağlandığına göndermede bulunan dolaylılık (indirectivity) olarak ortaya çıkar. Kanıtsallıkta konuşur, olay anında değil, olay sonrasında devreye girer. Bilgi, olay sonrasında oluşan ortamın sunduğu imkânlardan elde edilir.

Bocnurd ağzinda kantsallik, fiillere eklenen -(I)ddI(r), -dI, -ūdi ekleri ve isimlere eklenen IdI -(y)IdI -(y)dI, imiş -(y)imiş yapılarıyla işaretlenmektedir. Bunlar arasında kanıtsallık ifadesi için -(I)ddI(r) ve IdI -(y)IdI -(y)dI yapıları karakteristiktir. -ūdi eki, kantsallı̆̆ın geçmiş zamanda bildirilmesinde kullanılmaktadır. Sistemde kanıtsallık işaretleyicilerinin türü ve sayısı, tarihsel gelişimin ve dil etkileşimlerinin sonucunda şekillenmiştir. Buna göre de Bocnurd ă̆zının kanıtsallık tablosu, O ğuz grubunun diğer üyelerine göre bir dereceye kadar farklılaşmıştır.
\end{abstract}

\section{Anahtar Kelimeler}

Horasan Türkçesi, Bocnurd ă̆zı, kanıtsallık, dolaylılık, dil ilişkileri.

\section{Abstract}

Evidentiality is a grammar category reporting which sources the factual information is obtained from. Evidentiality in Turkic appears as indirectivity referring to indirect information. The talker comes into play after the event, not during the event. Information is obtained from the opportunities which are presented by the environment arisen after the event.

Evidentiality in Bocnurd dialect is marked by the structures of -(I)ddI(r), -dI, -ūdi suffixes attached to verbs and IdI -(y)IdI -(y)dI, imiş -(y)imiş suffixes attached to nouns. Among them, the structures of -(I) $\mathrm{ddI}(\mathrm{r})$ and $\mathrm{IdI} \sim-(\mathrm{y}) \mathrm{IdI} \sim-(\mathrm{y}) \mathrm{dI}$ are characteristic for evidentiality expression. $\bar{u}$ di suffix is used for stating evidentiality in the past tense. The type and number of evidentiality markers in the system has been formed as a result of historical developments and language relationships. Accordingly, the evidentiality table of Bocnurd dialect has been differentiated to some extent according to other members of Oghuz group.

\section{Keywords}

Khorasan Turkic, Bojnurd dialect, evidentiality, indirectivity, language relationships.

\footnotetext{
* Doç. Dr., Necmettin Erbakan Üniversitesi, Sosyal ve Beşeri Bilimler Fak., Türk Dili ve Edebiyatı Bölümü, e-posta: dogan.talip@gmail.com
} 


\section{Giriş}

Kanıtsallık (evidentiality), ifade edilen olay hakkındaki bilginin hangi kaynaklardan elde edildiğini bildiren, bilginin kaynağına göndermede bulunan dil bilgisi kategorisidir. Konuşurun dile getirdiği bilgi, değişik kaynaklar üzerinden temin edilmiş olabilir. Bilgi, söz gelişi bizzat görmek suretiyle yani herhangi bir aracı olmaksızın elde edilebileceği gibi, ikinci veya üçüncü el kaynaklar aracılığıyla, sebep-sonuç ilişkisiyle ya da dokunma, koklama gibi duyu organlarıyla da elde edilebilir. Kanıtsallık kapsamında ayrıca, bilgi kaynağının ve türünün dayanak noktalarının nasıl gösterildiği ve neler olduğu da incelenir. Dillerin çoğunda “Olay duyuldu mu veya dolaylı bir kanıt aracılığıyla mı öğrenildi?" gibi, bir ifadenin dayandığ kanıtın doğasının gösterilmesi beklenir (Aikhenvald 2004; Cornillie 2009: 45; Aslan Demir 2013: 409-410).

Kanıtsallık, önceleri kiplik kategorisinin bir alt dalı olarak değerlendirilmiştir. Bu bağlamda kanıtsallık; Palmer (1986)'da epistemik kiplik (epistemic modality), (2001: 24-47)'de ayn zamanda önerme kipliği (propositional modality) kategorisinde ele alınmıştır. Csató (2000: 37) kanıtsallığın, semantik açıdan epistemik kiplik içinde de değerlendirilebileceğini düşünmektedir. Ancak bugün literatürde kanıtsallık, kiplikten ayrı bir kategori olarak büyük ölçüde yerleşmiş durumdadır. Epistemik kiplik, konuşurun sahip olduğu bilginin kesinlik derecesi, doğru veya yanlışlı̆̆ı hakkındaki pozisyonuyla alakalıdır. Kanıtsallık ise bilginin kaynağının ne olduğunu, nasıl elde edildiğini ele alır ve bu yönüyle epistemik kiplikten ayrılır. Bu farklılık iki kategorinin birbirinden ayrıştııılmasında hareket noktası olmuştur (Aslan Demir 2013: 409; Üzüm 2017: 69-77).

Dünya dillerinde bilginin kaynaklarının ifade edilmesi açısından farklılıklar bulunmaktadır. Bir başka açıdan dünya dilleri kanıtsallığı, birbirinden faklı sistemlerle ortaya koymaktadır. Kanıtsallık sistemi dünya dillerinde iki geniş gruba bölünmektedir: (i) Bilginin kaynağı için bir kanıtın olduğunu, kanıtın kaynağını belirli duruma getirmeden anlatanlar. (ii) Kanıtın türünü (görerek, çıkarımla, nakille vb.) de bildirenler1. Birinci sisteme dâhil olan dillerde kanıtsallık için işaretlenen ifade, bilinen bir konunun kabulüne atıfla belirtilir. Belirsiz, tanımlanmamış bir bilgi kaynağının varlığı ve bilginin bir aracı yoluyla, dolaylı şekilde elde edildiği varsayılır. Bu sistem Türk dilleri, kimi İranî diller ve Fin-Ugor dillerinin karakteristik özelliğidir. İkinci tipe giren dillerde kanıtsallık, belirli olan bilgi kaynağının türlerine ve sayısına göre alt dallara ayrılır (Aikhenvald 2003: 3).

Türkçede kanitsallık kategorisi, bilginin dolaylı yollardan elde edildiğine göndermede bulunan dolaylılık (indirectivity) olarak öne çıkar. Kanıtsallığın içerdiği bir kategori olan dolaylılık, bağlama göre duyma, çıkarım, kanıt gösterme, varsayma, algılama gibi ayırtıları bildirir. Dolaylılıkta konuşurun, olaya şahit olmadığı ya da bilinçli olarak katılmadığı iması vardır. Konuşur, olay anında değil, olay sonrasında devreye girer. Bilgi, olay sonrasında oluşan ortamın sağladığı imkânlardan elde edilir. Olay duyulmuş, çıkarım veya varsayım yoluyla bilinmiş, duyularla algılanmış vb. olabilir. Diğer yandan dolaylılık ironi, tevazu gibi anlamlar ile yeni bilgi özelliğinde keşif, farkına varma, sürpriz, zihinsel açıdan hazır olmama, beklenenin tersinde bir tespit, beğenme gibi bağlama göre şekillenen yorumların sunulmasını sağlar. Dolaylılık düzleminde işaretlenen bilgi, başka bir kaynağın referans gösterilmesi suretiyle dolaylı şekilde anlatılır (Johanson 2000, 2003: 274-285; Bacanlı 2006; Demir 2012: 97-98). Türkçe

Dünya dillerinin kanıtsallık açısından sınıflandırılması için ayrıca bk. Cornillie (2009: 46). 
gibi dolaylılık tipli kanıtsallık sistemlerinde bilginin nasıl elde edildiği bir ölçüt olarak yer tutmaz. Örneğin Türkiye Türkçesinde kanıtsallığın işaretleyicileri $-m X$ ş ve imiş - $(y) m X$ ş ile bilgiye dolaylı yolla veya bir aracı yardımıyla sahip olunduğuna dikkat çekilir. - $m X$ ş ve imiş, türlü dolaylı bilgi kaynaklarını tek başlarına bildirme imkânına sahiptir. Türkçe bu yönüyle, kanıt türlerinin ayrı ayrı işaretleyicilerle sunulduğu dillerden farklılık taşımaktadır. Tabii, dil içi ve dil dişı bağlamın desteğiyle Türkçede de bilginin kaynağını belirli duruma getirmek mümkün olabilir (Aslan Demir 2013: 410). Örneğin, 'Oda yeterince ısınmış.' gibi bir cümlede -mış, olaya dair bilgi duyu organlarıyla elde edildiği için algıya dayalı kanıt türünü sunmuştur.

Bilgi kaynakları, yani kanıt türleri bilginin elde edilme yollarından hareketle bilim adamları tarafından sınıflandırılmıştır. Willet (1988), Aikhenvald (2004), Plungian (2010) gibi başlıca çalışmalarda kanıt türlerinin çeşitli bakış açlarıyla sınıflandırılması konu olmuştur (bk. Plungian 2010: 35-38). Kanitsallık kategorisini, Türkçe üzerinde inceleyen Johanson ise nakle dayalı, çıkarıma dayalı ve algıya dayah olmak üzere üç tür bilgi kaynağına dayandırmıştır. Nakle dayalı bilginin temeli yabancı bir kaynak, başkasından duyulan söz, söylenti ya da dedikodu vb.'dir. 'Bakan hastaymış.' 'Bakan, söylentiye göre hastaymış.' cümlesi, bakanın hastalı̆̆ı hakkında haber alan biri tarafından söylenmiştir. Çıkarıma dayalı bilginin temelinde kuramsal fikir, mantıkî sonuç gibi hareket noktaları vardır. 'Uyumuşum.' 'Belli ki uyumuşum.' cümlesi yeni uyanmış biri tarafından dile getirilmiştir. Algıya dayalı türde birinci el bilginin temeli, olayın duyu organlarıyla (görme, işitme, dokunma, tatma gibi) doğrudan algılanması yahut olayın sonuçları, izleri üzerinden dolaylı algılanması gibi hususlara dayanır. 'İyi çalıyormuş.' 'Duyduğum kadarıyla iyi çalıyor.' cümlesi, çalan kişiyi az önce dinlemiş birine aittir (2003: 274275).

Eski Türkçede kanıtsallık -mIş eki ile karşılanmıştır. Çağdaş Türk dili alanında kanıtsallığın -mIş ile bildirilmesi, Oğuz grubu lehçelerinde (Türkiye, Gagavuz ve Azerbaycan Türkçeleri) korunmuştur. - $m I s ̧$ tipli kanıtsallık ayrıca Tuva Türkçesinde ( $-m X s ̧ \sim-b X S ̧ s--v X s ̧$ biçimleriyle) ve Saha Türkçesinde ( $-m X t \sim-b X t \sim-p X t$ biçimleriyle) geçerlidir. Yaygın olmamak kaydıyla Özbek ve Yeni Uygur Türkçelerinde de bu grup kanıtsallığın örnekleri vardır. Kanıtsallık ifadesi için mIş'ın yerine Türk dilinin çoğu lehçesinde ${ }^{2}$, ancak Çağatay Türkçesinde yenilenmiş olan $G A n(d u r)<-G A n$ turur yapısı işletilmektedir. Eski Türkçe döneminden sonra yenilenen bir diğer kanıtsallık işaretleyicisi ise $-(I) p(D)(I)(r)<-(I) p$ turur yapısıdır. Eski Oğuz Türkçesinde $-(y) U p$ $(d U r)(U r)$ biçiminde tanıklanan yapı, Türkiye Türkçesinde kalmamıştır. -(I)p(D)(I)(r) yapısı, GAn(dur) yapısına göre genellikle daha fazla odaksıllık taşır. -GAn(dur) hem teşhissel (diagnostic) hem de genellikle tarihsel (historical) anlatımlarda kullanılmıştır. -(I)p(D)(I)(r)'ın ise teşhissel (diagnostic) anlatımlarda kullanılma eğilimi baskındır. Teşhissel ifadelerin odaksıllık derecesi daha yüksektir. Türk dili alanında ek-fiilin kanıtsallık biçimleri ise, ermiş ve erken'e dayanmaktadır. Bunlar, söz gelişi Türkiye Türkçesinde imiş -(y)mXş, Türkmen Türkçesinde mIş ve eken biçimlerindedir (Johanson 2000: 61-73; KTLG-F 2006: 35-113). Erken'den gelişen biçimlerin kimi lehçelerde kanıtsallık için kullanılmadığı, buna mukabil zarf-fiil yaptığı ayrıca belirtilmelidir. Örneğin Türkiye Türkçesinde iken biçimi, sadece zaman bildiren zarf-fiil özelliğine sahiptir.

Türkiye Türkçesinde $-m X s ̧$ ve imiş -(y)mXş (<er-miş) yapılarıyla işaretlenen kanıtsallık çeşitli yönleriyle incelenmiştir ${ }^{3}$. İsimlerle veya birleşik çekimlerle kullanılan imiş -(y)mXş unsurları, bitmişlik bildiren $-m X_{S ̧}$ ekine sahip olmasına rağmen zaman işlevini kaybetmiş

\footnotetext{
Oğuz grubunda Türkmen Türkçesi, Karluk ve Kıpçak grubu lehçeleri, Güney Sibirya lehçeleri ve Çuvaş Türkçesi. Bu çalışmalar için ayrıca bk. Aksu-Koç \& Slobin (1986), Schroeder (2000), Bacanlı (2008), Gül (2009), Demirci (2010).
} 
durumdadır. imiş -(y)mXş unsurları, Türkiye Türkçesinde yalnızca kanıtsallık göstermektedir. Fiillere eklenen $-m X s ̧$ unsurunun ise kanıtsallık yanında geçmiş zaman işlevi de vardır (Csató 2000: 34-37). Türkiye Türkçesi alanında kanıtsallık işaretleyici olarak ayrıca -(y)XK eki kaydedilmiştir. Özellikle Yörük ve Türkmen diye bilinen yarı göçebe grupların ağızlarında kullanılan -(y)XK, -mXş'a göre daha yüksek düzeyde odaksıllık sunmaktadır (bk. Demir 2012: 108-113).

Kanıtsallık, olayın (fiilin) gerçekleşmesinden sonra oluşan safhasıyla ilgili olduğu için, aynı zamanda bir görünüş türü olan sınır sonrası (postterminal) bakış ile kesişmektedir4. Bu bağlamda her iki kategori de fiillerin gerçekleşmesinden sonraki evresi ve durumu üzerinde işlem görür. Fiillerin gerçekleşmiş sayılması, ancak kritik sınırının aşılmasıyla mümkün olur. Fiillerin kritik sınırı ise kılınış özelliklerine göre farklılık arz eder. Son sınırı vurgulayan fiillerin (öl-, bayıl-, bozul- vb.) gerçekleşmesi için kritik sınır, bitiş sınırı yani son sınırdır. Bu tür fiillerin gerçekleşmesi, son sınırının aşılmasına bağlıdır. Bu fiillerde olay, gerçekleştikten sonra aynı zamanda tamamlanmış olur. Daha sonra olayın devam etmesi söz konusu değildir. Örneğin; "Bozulmuş. Bayılmış." cümlelerinde olay hem gerçekleşmiş hem de bitip tamamlanmıştır. Sınır vurgulamayan fiillerde belirgin bir sınır yoktur. Olayın gerçekleşme biçiminde önemli olan, sürektir. Bu tür fiiller çalış-, iç- gibi dinamik (dynamic) ya da sahip ol-, yaşa- gibi dură̆an (nondynamic) içeriğe sahip olabilirler. Ön sınırı vurgulayan (uyu-, otur-, yat-, uç- vb.) fiillerde ise kritik sınır diğer bir deyişle gerçekleşme noktası, başlangıçtır. Bu tür fiillerin, gerçekleşmesini sağlayan bir başlangıç evresi bir de bunu izleyen durağan evresi bulunmaktadır. Örneğin saklan- fiilinde bir duruma girme (saklanma durumuna girme) ve bunu sürdürme (saklanma durumunda kalma) şeklinde iki evreli iç dinamik vardır ${ }^{5}$. Ön sınırı olan fiiller, gerçekleştikten sonra devam etme potansiyeli taşıdığ 1 için $-m X X_{\text {ş }} l_{1}$ ifadelerde şimdiki zaman yorumuna da izin verir. Örneğin "Saklanmış." cümlesi, derin yapıda "Saklanmıı̧ ve hâlâ saklanıyor." anlamını içerir. Kısaca olay, bu tür örneklerde hâlihazırda yani konuşma anında da devam etmektedir.

\section{Bocnurd ${ }^{6}$ Ağzında Kanıtsallık İşaretleyicileri}

Bocnurd ağzında kanıtsallık kategorisini, fiillere eklenen -(I)ddI(r) ve -dI ekleri ile ek-fiilin çekimlerinden oluşan ve isimlere eklenen $I d I \sim-(y) I d I \sim-(y) d I$ ve imiş -(y)imiş unsurları temsil eder. Bunlar arasında kanıtsallık ifadesi için $-(I) d d I(r)$ ve $I d I \sim-(y) I d I \sim-(y) d I$ yapıları hâkimdir. Kanıtsallık geçmiş zamanda ise, $-\bar{u} d i$ ekiyle sunulmaktadır. Bocnurd ağzının sistemindeki kanıtsallık işaretleyicilerinin türü ve sayısı, tarihsel gelişime ve dil etkileşimlerine bağlı olarak şekillenmiştir. Bunun sonucunda Bocnurd ağzının kanıtsallık tablosu, Oğuz grubunun diğer üyelerine göre bir dereceye kadar farklılaşmıştır. Eldeki çalışmada Bocnurd ağzındaki kanıtsallık işaretleyicileri üzerinde durulmuştur. Verilen örnekler Bocnurd ağzından metinlerin olduğu Bozkurt (1975), Fázsy (1977), Doğan (2016), Doğan (2017a)'ya dayanmaktadır. Birbirinden farklı kaynaklardan alınan örnekler, ortak bir çeviri yazı alfabesiyle yazılmıştır. Örnekler ayrıca, sayfa numarası ve metin numarasıyla sunulmuştur.

Sınır sonrası bakış hakkında bk. Aslan Demir (2016: 47-48).

Kılınış hakkında bk. Karadoğan (2009).

Bocnurd, İran'ın Kuzey Horasan eyaletinde bulunmaktadır. Kuzey Horasan eyaletinin yönetim merkezi olan şehir, Tahran'a 701 km uzaklıkta yer almaktadır. Bocnurd, Horasan bölgesinde Türklerin yoğun olduğu bölgelerden biridir. Bocnurd'da Türkler, Fars ve Kürt unsurlarla birlikte yaşamaktadır (Heyet 2008: 299).

$7 \quad$ Krş. Azerbaycan Türkçesinde $-m X s ̧,-(y) X b(d X r)(l A r)$ ve imiş (Kazımov 2010: 96, 229-231); Türkmen Türkçesinde - An, -(I)pdIr ve -mIş, eken; Türkiye Türkçesinde -mXş ve imiş -(y)mXş (Aslan Demir 2013: 411). 


\section{1. Fiillere Eklenen İşaretleyiciler}

\section{1. 1. -(I) $d d I(r)<(-(X) p$ turur $)$}

-(I)ddI(r), Bocnurd ağzında kullanılan geçmiş zaman eklerindendir. -(I)ddI(r) eki, -(X)p turur $>-(X) p t u r>-(I) p t I r>-(I) p d I r>-(I) b d I r>-(I) d d I r>-(I) d d I$ yönünde bir gelişmeyle ortaya çıkmıştır8.

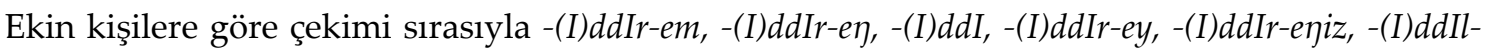
len biçimlerindedir9. -(I)ddI( $r$ ), fiillerde kullanıldığında vurgulu söylenmektedir. Geçmiş zaman eki -(I)ddI(r), aynı zamanda kanıtsallık kategorisinin işaretleyicisidir. Sistemde kanıtsallık işlevi için -(I)ddI(r) ile rekabet edebilecek düzeyde yaygınlaşmış bir başka ek yoktur. Bu yüzden (I)ddI(r), kanıtsallığın bütün türlerini (nakle dayalı, çıkarıma dayalı ve algıya dayalı) sunma potansiyeline sahiptir. -(I)ddI(r)'ın kanıtsallık işaretleyicisi olması, fiilin gerçekleşmesinden (kritik sınırının aşılmasından) sonrasını yansıtabilme özelliğinin sonucudur. Bir diğer deyişle sınır sonrası bakışı sunan -(I)ddI(r), olayın görüş açısından çıktıktan sonra gözlemlenmesini sağlayarak dolaylı bilgiye zemin hazırlamaktadır. -(I)ddI(r) ekiyle konuşurun bizzat katılmadığı ve tasarlamadığı, bilinçli olarak kontrol etmediği olaylar karşılanmaktadır. Böyle bir durumda bilginin elde ediliş tarzına, bağlama ya da diğer sözlüksel birimlere göre çeşitlenebilen "şaşırma, hayıflanma, birden hatırlama ya da fark etme, beklenmedik durum, zihnen hazırlıksız yakalanma" gibi yan anlamlar da dâhil olmaktadır. Ancak gelişen bu yan anlamlar, ekin asli işlevleri arasında değildir. Aşağıda -(I)ddI(r) ekiyle ifade edilmiş olan kanıtsallık türlerine örnek cümleler sıralanmıştır. (1) numaralı örnekte bilginin kaynağı nakle dayalıdır. Konuşur, bilgiyi başkasından duyarak edinmiştir. Nitekim cümlede geçen duydi ki ifadesi de bunu açıkça ortaya koymaktadır. (2), (3), (4) ve (5) numaralı örneklerin bilgi kaynağı çıkarıma dayalıdır. Konuşur, niyet etmediği hâlde karşılaştığı olaylar hakkında çeşitli yollarla bilgi sahibi olmuştur. Bu örneklerde bilgi, belirli delil ve sonuçlar aracılı̆̆ıyla sağlanmıştır.

(1) duydi ki og̀li o şerde aşşig olitdi. dédi ki oğil. dédi he. dédi sen her neme istiyè, men seniçin aliyem (F: 254/79-82),

‘Duydu ki oğlu o şehirde âş̧ı olmuş. Dedi ki: -Oğul. Dedi: -He. Dedi: -Sen her ne (kimi) istersen, (onu) senin için alırım.'

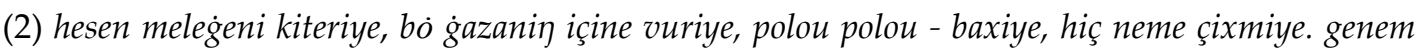
diye polou, polou, baxiye, hiş çıxmiye. diye hey, bo pederseyle meni allatitdilen, muni og̀ırletdillen (F: 139-140/46-48),

‘Hasan kepçeyi kaldırıyor, bu kazanın içine vuruyor, (diyor:): -Pilav, pilav! Bakıyor hiçbir şey çıkmıyor. Yine diyor: -Pilav, pilav! Bakıyor, hiçbir şey çıkmıyor. Diyor: -Bu köpekoğulları beni aldatmışlar, bunu çalmışlar!'

(3) şu vexti duydi ġendimiz itiddi,

ézimnen dédim işimiz bitiddi. (GG: 126/224),

'O zaman anladık şekerimiz kaybolmuş,

Kendi kendime dedim, işimiz bitmiş.'

(4) vexti ki kiçiyidi istiyerdi ki bihiy oley,

ki bihiy olmedi yu şu çā̆̆ yem olmeddirey. (İs: 222),

\footnotetext{
8 Bu ek, Bocnurd ağzının yer aldığı Bozkurt (1975: 189)'da -(I)pdI(r) biçiminde, Fázsy (1977: 113-114)'de -(I)pdI(r) (I)tdI(r) biçimlerinde kaydedilmiştir.

$9 \quad-(I) d d I(r)$ eki hakkında ayrıca bk. Doğan (2017b).
} 
Küçüklüğümüzde isterdik, büyük olalım,

Büyük olmadık ve çocuk da olmamışız.

(5) bu dévlerden birni gidiye, bir poşte odin cenelden yigiziye, getiriye. nezer vağti gériye, diye bah bax gidipdi, neme odin getiripdi. do men ézim gidim cenele, birden ġopartim, mesġere édipdilen ézlerini odin getirmaggleriynen. (F: 132/53-55),

'Bu devlerden biri, ormandan gidip bir posta odun topluyor, getiriyor. Nazar (odunları) görünce, diyor: -Bak bak, gitmiş nasıl odun getirmiş. Dur ben kendim ormana gideyim, birden toplayayım, kendilerini (böyle) odun getirmeleriyle maskara etmişler.'

(6) ile (10) arasındaki cümlelerde ise bilgi, algıya dayalı yollarla elde edilmiştir. Konuşurlar olayların gerçekleştiğini (6), (7) ve (8) numaralı örneklerde görmek, (9) numaralı cümlede dokunmak, (10) numaralı cümlede koklamak suretiyle anlamışlardır. Bu tür örnekler, aynı zamanda teshişşel (diagnostic) ifadelerdir. Bocnurd ağzında -(I)ddI( $r$ ) yapısının, özellikle teshişşel (diagnostic) bildirimlerde kullanılması karakteristiktir. -(I)ddI(r) ile sunulan bu olaylarda ayrıca yüksek düzeyde bir odaklılık söz konusudur. Bundan dolayı cümlelerde (I)ddI(r)'ın, sık sık odaksıl şimdiki zaman işaretleyicileriyle birlikte kullanıldığı görülmektedir. Çünkü odaksıl şimdiki zaman işaretleyicileri, konuşma anı ile eş zamanlı gerçekleşen olayları bildirir. -(I)ddI(r)'ın bu işaretleyicilerle birlikteliği ve uyumu, yüksek odaksıllığa da zemin hazırlamıştır. Söz gelişi (6) ve (7) numaralı cümlelerde olayların konuşma anıyla örtüştügüunü bildiren baxiye $k i$ 'bakıyor ki' ve baxdim ki ‘baktım ki' gibi ifadelerin varlığı, -(I)ddI(r)'ın odaksıl yönüyle ilgilidir:

(6) vexti geliye çeşmeniๆ istine, baxiye ki bo ġz heniz orde otırtdi (F: 182/144),

'Çeşmenin başına geldiğinde bakıyor ki, bu kız hâlâ orada oturuyor (oturmuş halde.)'

(7) men geldim ki oni için çay o çérey getirim, baxdim ki o ikki sani şiri tutipdi, ineylerī yirine baġletti, yiri şoxm édiye (F: 233/110),

'Ona çay ve ekmek getireyim diye geldim, baktım ki o iki tane aslanı tutmuş, ineklerin yerine bağlamış, yeri sürüyor.'

(8) bu suden su işdi yo gitdi, ta bir deste touġe yétişdi. dedi ey atem, ge ki bóle kimkidi çele biyabane biraxitdillen (F: 181/108-109),

'Bu sudan içti ve bir grup tavuğa rastlayıncaya kadar gitti. Dedi: -Ey babacığım, gel, bunlar kimindir ki, dışarıya bırakmışlar?'

(9) bo bedbextle yem geldilen, temam suvin içinde izaldilen érte tördilen goyrig̈i yexletdi (F: 151/37),

‘Bu bahtsızlar da geldiler, tamamı suyun içine uzandılar. Sabah kalktılar, kuyrukları buz tutmuş (idi).'

(10) nene gulimi门 issi heniz hevālde,

g̀ulāb sepiddi sen diyen şemālde. (İs: 111),

‘Gül ninemin kokusu hâlâ avluda,

Gül suyu serpilmiş sanki rüzgâra.'

\section{1. 2. $-d I$}

Bocnurd ağzında $-d I$ eki esas itibarıyla görülen geçmiş zaman işlevinde kullanılmaktadır. Bunun yanında $-d I$ ekine, yer yer kanıtsallık ifadeleri için de başvurulmuştur. Aşağıda bu çerçevede verilen ilk iki örnek, çıarıma dayalı kanıt türüne aittir. Bilgiye (1) numaralı cümlede 
varsayılarak, (2) numaralı cümlede sebep-sonuç ilişkisine bağlı olarak ulaşılmıştır. (3) numaralı cümlede görmek suretiyle elde edilen algıya dayalı bilgi söz konusudur:

(1) niçe ginnen sore bu soltan éldi. bo kiçi og̀li geldi, gardaşlerine dédi gelin gidey, bizin atemiz neme vasiyet étdi (F: 218/7-8),

‘Birkaç günden sonra bu sultan öldü. Bu küçük oğlu geldi, kardeşlerine dedi: -Gelin gidelim, babamız (bize) ne vasiyet etmiş?'

(2) béle ki héç kim biçirāò ġālmedi,

eger em ġāldi êzi lam almedi. (GG: 94),

'Öyle ki hiç kimse işıksız kalmadı,

Eğer kaldıysa da kendisi lamba almamıştır.'

(3) o teref bu terefe, o teref bu terefe, baxiye, gérye bir ziynedi, bu ziynelerden yixari gidiye, baxiye $k i$ bir damin istine çıxdi (F: 289/46),

'O tarafa bu tarafa, bakıyor, bir merdiven görüyor. Bu merdivenlerden yukarı çıkıyor, görüyor ki, bir damın üstüne çıkmış.'

Türkiye Türkçesinde masalların anlatımında kanıtsallık ekine (-mXş'a) başvurulmaktadır. Ancak Bocnurd ağzında masal anlatımlarında bu tür ifadeler - $d I$ ekiyle sunulmaktadır. Burada bir metin türünün anlatımıyla ilgili durum söz konusudur. Masallarda art arda, birbirini takip eden olaylar - $d I$ ekiyle sıralanmaktadır. Ancak - $d I$ ekiyle sıralanan olaylar arasında kanıtsallığın herhangi bir türünün ifadesi için -(I)ddI(r) eki işletilmektedir. Örneğin,

(1) vexti gitdi bariganiๆ içine, gèrdi ki şu giz onde yatitdi (F: 254/88),

'Sarayın içine gitti (gittiği zaman), gördü ki o kız orada yatmış.'

\section{1. 3. $-\bar{u} d i$}

Bocnurd ağzında kullanılan - $\bar{u} d i$ yapısı, -(I)p eki ile -di ekini alan $e r$ - fiilinin birleşmesinden oluşmuş birleşik çekime dayanmaktadır. $-\bar{u} d i$ yapısının gelişim seyri şu şekilde olmuştur: $-(\mathrm{X}) p$ erdi $>-(X) p$ edi $>-(I) p$ idi $>-(I) b d i>-u v d i>-\bar{u} d i^{10}$. Bocnurd ağzında $-\bar{u} d i$ yapısı, kanıtsallık bildirimlerini geçmişe konumlandırmaktadır. $-\bar{u} d i$ birleşiğinde $-\bar{u}<-(I) p$ unsuru, kanıtsallık türlerini işaretler; -di unsuru ise işaretlenen bu kanıtsallığı geçmişe taşır. Aşağıdaki örneklerde $\bar{u} d i$ ekiyle, görsel algılama yoluyla kazanılmış olan bilgiler geçmiş zamanda aktarılmıştır:

(1) quffiledi u şuşelerin ġırōvini arrıtdi,

gizgiye baxdi, çă̆ayidi, genem çă̆alı̆̆ étdi.

àgişġeden baxdi dize, gérdi ki ġar yā ă ūdi,

pāy ve pāy o cir çekmeni gezdi u tā ki tapdi,

rextimizi hay ist $u$ astli gidi,

gorxince ki hay aneden xebbeki dîze baxdi,

ikki ġeriş ğar yā̆ğüdi, otırūdi hevālde. (ISS: 46/43-44),

'Üfledik ve camların kırağısını erittik,

Aynaya baktık çocuktuk, gene çocukluk ettik.

Pencereden baktık dışarıya, gördük ki kar yağmıştı,

Tek tek çizmeleri aradık ve bulduk,

Elbiselerimizi üstlü altlı giydik,

Anneden korkunca sessizce sokağa baktık,

İki karış kar yağmıştı, oturmuştuk avluda.'

10 Bu yapı hakkında bilgi için ayrıca bk. Doğan (2017b). 
(2) gitdim emumi hem zindannen çixartdim ve dalannen géşdiy, garī demine yétişdiy. ikki sani nigehbanle yatūdilen. (F: 281/78-79),

'Gittim amcamı da zindandan çıkardım ve geçitten geçtik, mağaranın önüne yetiştik. İki tane bekçi yatmışlardı.'

\section{2. İsimlere Eklenen İşaretleyiciler}

\section{2. 1. $I d I \sim-(y) I d I \sim-(y) d I<(e r-t i)$}

Bocnurd ağzında ek-fiille kanıtsal bilginin işaretlenmesi daha çok IdI -(y)IdI -(y)dI biçimleriyle olmaktadır. Bu biçimler, $i$ - ek-fiilinin görülen geçmiş zaman eki - $d I^{\prime} y ı$ almış hâlidir.

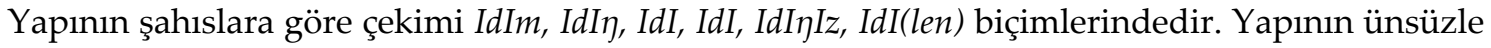
biten sözcüklerden sonra kullanılan IdI biçimi ve ünlüyle biten sözcüklerden sonra kullanılan -(y)IdI biçimi karakteristiktir. Ünlüyle biten sözcüklere eklenen -(y)dI biçimi yaygın değildir.

İmiş < er-miş biçimi, Bocnurd ağzında sınırlı olarak kullanılmıştır. imiş'in işlev alanı, geniş ölçüde $I d I<e r-t i$ biçimiyle doldurulmuştur. IdI biçimi hem görülen geçmiş zamanı hem de kanıtsallığı, yani bilginin dolaylı yollardan edinildiğini bildirmektedir. IdI'nın hangi işlevinin geçerli olduğu bağlamda anlaşılmaktadır. Aşağıda IdI -(y)IdI biçimlerinin kanıtsallık türlerini bildirdiği parçalar sunulmuştur. (1) numaraları örnekte ulaşılan bilgi, nakle dayalıdır. (2) numaralı örnekte sonuçlardan öğrenilen, (3) ve (4) numaraları örneklerde ise delillerden elde edilen bilgiler söz konusudur:

(1) hemişe işi äh u efsūs idi, àxirde dédilen ki cāsus idi (GG: 76/50),

'Her zaman işi ah ve eyvahtı,

Sonunda dediler ki casusmuş.'

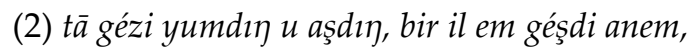

pis u yax̧̧ı şuyidi ġısmetimiz ... (İS: 88/140),

'Göz yumup açtın, bir yıl geçti annem,

Kötü ve iyi, buymuş kısmetimiz...'

(3) neceniך içinde bir muciri ġoyūdi anemiz,

bir alam şurdane yu noğl u nebāt, sen déme ġag்alıyidi.

culleri ġelüdilen ist iste sandiğxanede,

$\bar{a} \breve{g}$ puşe çeqūdilen, bilerdi mastmalıyidi (İs: 104/172),

'Dolabın içine bir sandığ

Bir dünya kuruyemiş, şeker, sen deme abur cuburmuş.

Giyecekleri istiflemişlerdi üst üste sandıkhanede,

Beyaz örtü örtmüşlerdi, anlardık ki gizlenmiş (saklanmış).'

(4) men bildim ki o ikki nefer ki men éldirdim birini adi yonci'édi ve obirinin adi hem ayó, ki meni yonci'niך ädine çăğıriyellen ve meni oniynen evezi tutitdillen (F: 279/35),

'Anladım ki öldürdüğüm o iki kişiden birinin adı Yonci'ymiş ve öbürünün adı da Ayo'ymuş. Çünkü beni Yonci'nin adıyla çağırıyorlar ve beni onunla karıştırmışlar.' 
Bocnurd ağzında $I d I \sim-(y) I d I \sim-(y) d I$ biçimlerine iki işlevin de (-dX'll ve $-m X X_{s}^{\prime} l_{1}$ anlatım) sığdırılması, bölgenin resmî ve baskın dili olan Farsçanın etkisinde gelişmiş görünmektedir. Nitekim Farsçada da ek-fiilin görülen ve öğrenilen geçmiş zaman kipi için aynı unsurdan, yani būden (بودن) fiilinden yararlanılmaktadır. Görülen geçmiş zaman kipinde bū (بود) 'idi', öğrenilen geçmiş zaman kipinde büde (بودن) 'imiş' yapıları işletilmektedir. Ek-fiilin şahıslara göre görülen

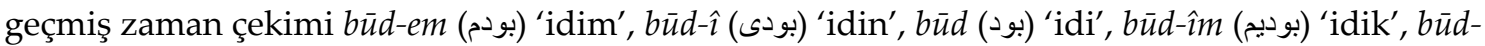

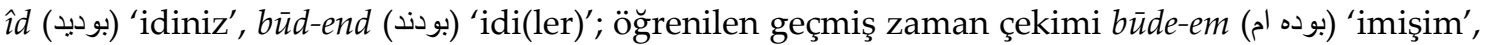

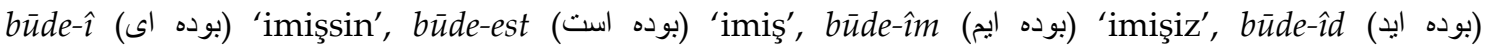

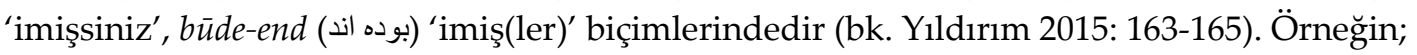

(1) Beç̧̧e budî̀,

'Çocuktunuz.'

(2) İn mevzū 'vāzihter būde est.

'Bu konu daha açık imiş.'

\section{2. 2. imiş -(y)imiş}

Bocnurd ağzında imiş -(y)imiş biçiminin yaygın görülmediği ve yerine genellikle IdI'nın işletildiği yukarıda belirtilmişti. Az sayıdaki örnek sadece Fázsy'nin metinlerinde geçmiştir (bk. 1977: 102). imiş, Bozkurt (1975: 182-183), Doğan (2016) ve Doğan (2017a)'a ait çalışmalarda ise kaydedilmemiştir. Horasan bölgesinde bulunan Dara-Gaz ve Lotf-ābād'da Azerbaycan Türkçesi ağızlarının da konuşulduğu tespit edilmiştir. Bunun sonucunda Azerbaycan Türkçesinin, Horasan Türkçesini etkilediği ifade edilmiştir (bk. Doerfer 1998: 274, 280). Bocnurd ağzında geçmiş olan -miş'li sınırlı örnekler de Azerbaycan Türkçesinin etkisine işaret etmektedir (Tulu 2009: 27). Kanıtsal bilgilerin (söz gelimi başkasından duyulan haberlerin aktarılması gibi) ifade edilmesi sırasında idi ve imiş'in kullanılma durumu, ayrıca bölge konuşurlarından da sorgulanmıştır. Konuşurlar bu durumda idi'yi, imiş'e göre daha çok kullandıklarını bildirmişlerdir. Bölgenin bir konuşuru olan Muhammed Hisari (yaş 38)'ye tarafımızca şöyle bir soru sorulmuştur:

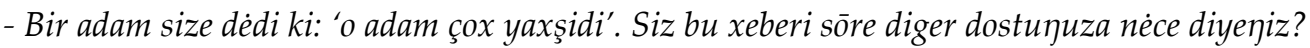

- 'o adam çox yaxşı idi', ya 'o adam çox yaxşı imiş'. ${ }^{11}$

'Bir adam size dedi ki: -O adam çok iyidir. Siz bu haberi sonra başka arkadaşınıza nasıl söylersiniz?'

-O adam çok iyiymiş (iyiydi), ya da -O adam çok iyiymiş.'

Muhammed Hisari cevap olarak daha çok birinci, yani idi'li cümleyi tercih ettiklerini bildirmiştir. Aşağıda Fázsy (1977)'nin metinlerinde geçen imiş -(y)imiş biçimlerinin kullanıldığı (1) numaralı örnekte nakle dayalı ikinci el bilgi, (2) numaralı örnekte sonuçlardan elde edilen çıarıma dayalı bir bilgi, (3) numaralı örnekte ise görerek sahip olunan algıya dayalı bilgi vardır:

(1) kiçi diye meni her kime berrsilen, men aliyem. bir peli hem derextin istinde imiş. (F: 192/6-7),

'Küçük diyor: Beni her kime verirlerse, ben alıyorum. Bir peri de ağacın üstündeymiş.'

${ }^{11}$ Bölgenin konuşuru için hazırlanmış olan bu metin, Bocnurd ağzına göre tarafımızdan oluşturulmuştur. 
(2) şişe elinnen dişdi o sindi yo munī enesiyem şu èvde èldi. bo şişe oniך omriyimiş. (F 196:112113),

'Şişe elinden düştü ve kırıldı ve bunun annesi de bu evde öldü. Bu şişe onun ömrüymüş.'

(3) Bo adem baxerdi ki bèle, munnen nèçe neferne gelitdi, şo cire hācii işi şu imiş. (F: 265/43),

'Bu adam bakardı ki böyle, buraya birçok kişi gelmiş, bu tür, hacının işi buymuş.'

Ayrıca, cümlede kanıtsal bilgiyi işaretlemek üzere idi ve imiş biçimlerinin bir arada kullanıldığı da olmuştur. Örnekte her iki unsurla nakle dayalı bilgiler anlatılmıştır:

(1) haciin em hiç kimi yox imiş, feğet bir xatini bār idi (F: 272/76),

'Hacının da hiç kimsesi yokmuş ama bir hatunu varmış.'

\section{3. -(I)ddI(r)'ın Kanıtsallık Dışı Kullanımları}

\section{1. Epistemik Kiplik İşlevi}

Bocnurd ağzında -(I)ddI(r) ekinin epistemik kipliğe izin veren kullanımları bulunmaktadır. Bu suretle -(I)ddI(r), kimi örneklerde "tahmin, ihtimal, varsayım", "şüphe, tereddüt" gibi anlamları bildirmiştir. Epistemik kipliği örneklendiren bu tür kullanımlar konuşurun, bilginin doğruluğu ya da gerçekliği hakkında güvence verme, gerçek olma olasılığını derecelendirme gibi yargılarını yansıtır. Aynı işaretleyici üzerinde epistemik kiplik ve kanıtsallığın kesişmesi zorunlu değildir ama muhtemeldir. Kanıtsallık işaretleyicilerinin çeşitli kullanımlarında birincil işleviyle beraber pragmatik düzeyde ortaya çıkan yan anlamları olarak epistemik anlamlar görülebilir (bk. Üzüm 2017: 70-72). Cümlelerde epistemik anlamlar, -(I)ddI(r) eki ile şayet 'belki' gibi sözlüksel unsurların ve bağlamın işbirliği sonucunda ortaya çıkmıştır. Aşağıdaki -(I)ddI(r)' ${ }_{1}$ örneklerin ilk ikisinde tahmin, son ikisinde ihtimal içerikli epistemik anlamlar vardır:

(1) ey baba, ge géç bölerden, böle her yérdedilen, indi birbirnen töy éditdilen, indi ole er o xatin olitdillen (F: 213/109),

‘Ey baba, gel bunlardan geç, bunlar her neredelerse, şimdi birbiriyle evlenmişlerdir, onlar karı koca olmuşlardır.'

(2) bo giz dedi he, dé şayet olerin eg̉li çekmetdi (F: 178/52),

'Bu kız dedi: -He, söyle, belki onların aklı ermemiştir.'

(3) feg̀et galdi bò gord. bo geçi dédi bardi, yoxdi, bo gord yétdi (F: 167/41-42),

'Sadece bu kurt kaldı. Keçi dedi: -Vardır yoktur (muhtemelen), bu kurt yemiş(tir).'

(4) baxdi yuo, xeber yoxdi. dédi bārdi, yoxdi, bó ceneverlerden birni buleri yètti. (F: 166/24-25),

'Baktı yok. Haber yoktur. Dedi: -Vardır yoktur (muhtemelen), bu canavarlardan biri onları yemiştir.'

3. 2. Görülen Geçmiş Zaman İşlevi: Kimi lehçelerin kanıtsallık işaretleyen eklerinde dil etkileşimlerine bağlı olarak işlev daralması ortaya çıkmıştır. Söz gelişi Azerbaycan Türkçesinin $m X$ ş ve $-(y) X b(d X r)(l A r)$ eklerinde Farsçanın etkisiyle kanıtsallık işlevi çekilmiş, görülen geçmiş zaman işlevi gelişmiştir. Benzer gelişmelere Türk dilinin başka alanlarında da rastlanmıştır. Sarı Uygur Türkçesi, Tibet dillerini hatırlatan kanıtsallık sistemini barındırmaktadır. Karay Türkçesinin de bu açıdan Slav ve Litvanya dillerinin etkisinde kaldığı tespit edilmiştir (Johanson 2003: 288). Bocnurd ağzının kanıtsallık sistemindeki bir kısım gelişmeler de yine Farsçayla etkileşimin sonucunda oluşmuştur. Farsçada öğrenilen geçmiş zaman kipi, görülen geçmiş zaman işlevinde de kullanılmaktadır. Örneğin, İmrūz nāhār çi hordê̂? ‘Bugün öğle yemeğinde ne yedin?' (Kanar 1997: 21). Buna benzer doğrultuda Bocnurd ağzında -(I)ddI(r) eki, 
bazen bilinen ya da görülen geçmiş zaman eki gibi kullanılmıştır. -(I)ddI(r) ekinin bu kullanımlarında dolaylılık anlamı yoktur. Diğer bir deyişle bilginin elde edilme yolu bildirilmemiştir:

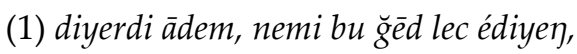

yōlini bîxud kec u mūvec édiyeๆ,

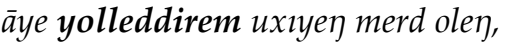

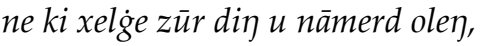

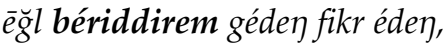

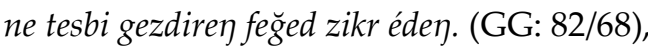

Diyordu (ey) insan, niye bu kadar çekişiyorsun,

Yolunu şaşırmış hâlde sapitıyorsun,

Ayet gönderdim okuyasın, mert olasın,

Halka şiddet gösteresin, namert olasın (diye ayet göndermedim),

Akıl verdim gidesin, düşünesin (diye),

Sadece tespih çekesin, zikredesin (diye akıl vermedim).

(2) érte genem tördi, gitdi şo çéle, çélde tikan ġopartdi, genem ilan geldi. İlan dédi ki, ey ġoce neme xeber getiripdirey (F: 177/27-28),

'Sabah yine kalktı, o kıra gitti, kırda dikenli çalı topladı. Yine yılan geldi. Yılan dedi ki: -Ey ihtiyar, ne haber getirdin?'

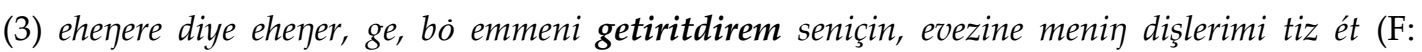
167/57),

‘Demirciye söyler: -Demirci, gel, bu torbayı senin için getirdim, karşıllğında benim dişlerimi keskinleştir.'

\section{Sonuç}

Bocnurd ağzının kanitsallık sistemini fiillere eklenen $-(I) d d I(r)$, $-d I$ ve $-\bar{u} d i$ ekleri ile isimlere eklenen $I d I \sim-(y) I d I \sim-(y) d I$ ve imiş $\sim-(y)$ imiş unsurları oluşturmaktadır. Sistemin yaygın eki (I)ddI(r)'ın, kanitsallığın bütün türlerini işaretleme eğilimi bulunmakla birlikte, teshişşel (diagnostic) ifadelerde kullanılması daha karakteristiktir. Bocnurd ağzında kanıtsal bilginin ifadesinde görülen geçmiş zaman eki $-d I$ da kullanılmıştır. - $\bar{u} d i$ eki, kanıtsallığın geçmiş zamanda bildirilmesini sağlamaktadır. Bocnurd ağzında ek-fiille kanıtsal bilginin sunulmasında IdI -(y)IdI -(y)dI yapıları yerleşmiştir. imiş -(y)imiş yapılarının kullanımlarına az rastlanmıştır. IdI -(y)IdI -(y)dI yapılarının iki işlevi (-dX'lı ve $-m X X_{s}^{\prime} l_{1}$ anlatım) aynı anda karşılar hâle gelmesi, bölgenin resmî ve baskın dili olan Farsçanın etkisine işaret etmektedir. Farsçada ek-fiilin görülen ve öğrenilen geçmiş zaman kipi, aynı unsurla yani büden (بودن) fiiliyle sağlanmaktadır. Söz konusu durum, Bocnurd ağzındaki gelişmenin de kaynağı olmuştur.

\section{Summary}

Evidentiality is a grammar category reporting which sources the factual information is obtained from. Evidentiality in Turkic appears as indirectivity referring to indirect information. The talker comes into play after the event, not during the event. Information is obtained from the opportunities which are presented by the environment arisen after the event. The type and number of evidentiality markers in the Bojnurd dialect system is formed as a result of historical development and language interactions. Accordingly, the table of evidence of Bojnurd dialect has been different to some extent in terms of the other members of Oghuz group. 
Evidentiality in Bojnurd dialect is marked by the structures of $-(I) d d I(r),-d I,-\bar{u} d i$ suffixes attached to verbs and IdI $\sim-(y) I d I \sim-(y) d I$, imiş $\sim-(y)$ imiş suffixes attached to nouns. The widespread use of the system -(I)ddI( $(r)$ tends to mark all types of evidence, but is more likely to be used in diagnostic expressions. In Bojnurd dialect, the past tense suffix - $d I$ was also used as the expression of evidence. $-\bar{u} d i$ suffix is used for stating evidentiality in the past tense. In Bojnurd dialect, $I d I \sim-(y) I d I \sim-(y) d I$ constructions were settled in the presentation of the evidence. The uses of imiş -(y)imiş structures are rare. The fact that the two functions (expressions with $-d X$ and $-m X s ̧$ ) of the $I d I \sim-(y) I d I \sim-(y) d I$ structures indicate the influence of the Persian, the official and dominant language of the region.

The past time of Persian adverb is provided with the same element, that is, the verb büden (بودن). The situation was also a source of development in Bojnurd dialect.

In addition, in Bojnurd dialect -(I)ddI(r) suffix has got uses that allow epistemic mode. In this case $-(I) d d I(r)$, in some cases it has meanings like "prediction, possibility, hypothesis", "doubt, hesitation".

On the other hand, in Bojnurd dialect -(I)ddI(r) suffix was used as a past time suffix under the influence of Persian.

\section{Çeviri Yazı İşaretleri Ve Kısaltmalar}

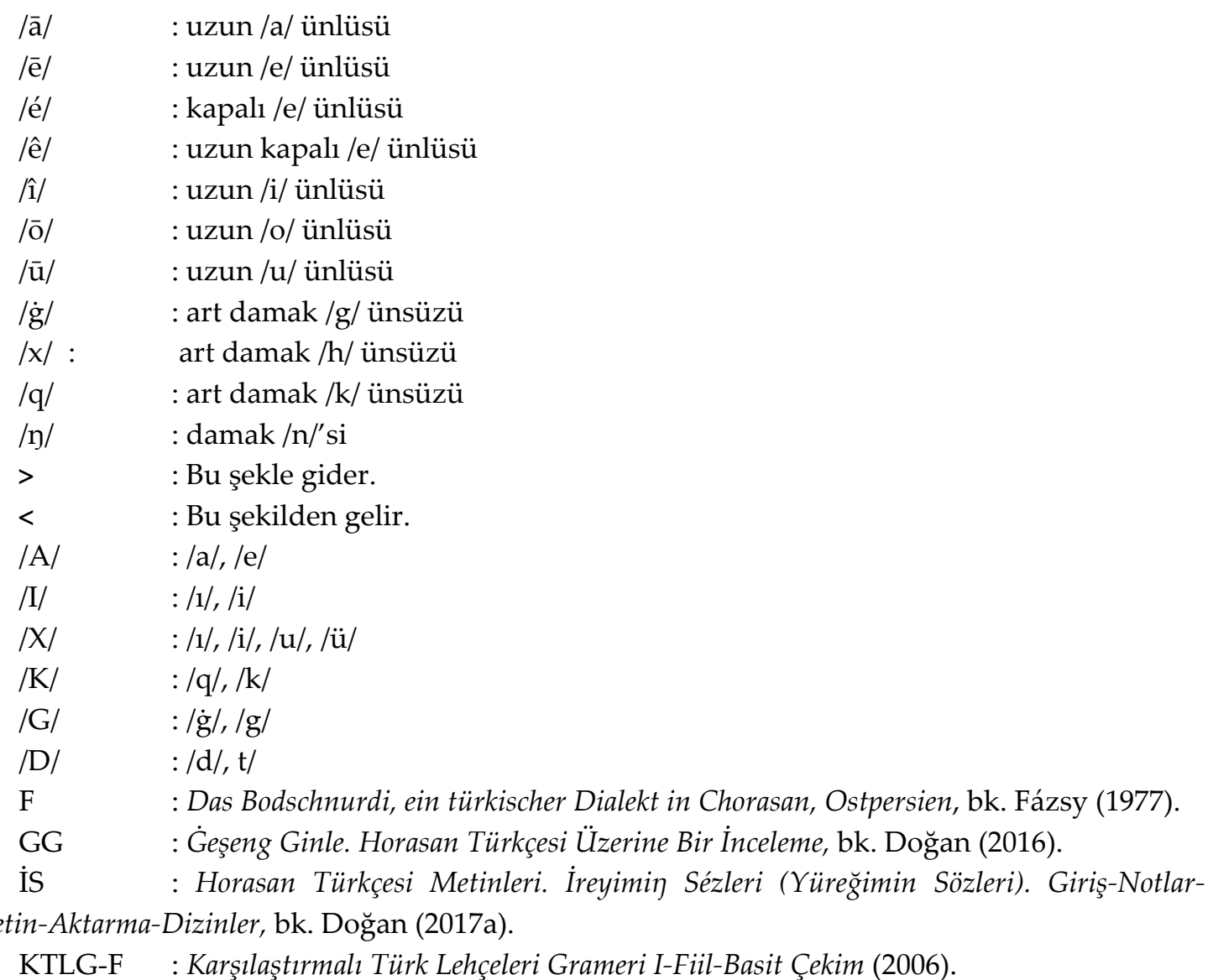




\section{KAYNAKLAR}

AİKHENVALD, Alexandra Y. (2003), “Evidentiality In Typological Perspective”, Studies In Evidentiality. Typological Studies In Language 54. (ed. Alexandra Y. Aikhenvald \& R. M. W. Dixon), Amsterdam \& Philadelphia: John Benjamins, 1-33.

AİKHENVALD, Alexandra Y. (2004), Evidentiality, Oxford: University Press.

AKSU-KOÇ, Ayhan \& SLOBİN, Dan I. (1986), “A Psychological Account Of The Development And Use Of Evidentials In Turkish", Evidentiality: The Linguistic Coding Of Epistemology, (ed. W. Chafe \& J. Nichols), Norwood and New Jersey: Ablex Publishing Corporation, 159-167.

ASLAN DEMIR, Sema (2013), “Türkmencede Kanitsallık/Evidensiyellik”, Leylâ Karahan Armağanı, Ankara: Akçă̆ Yayınları, 409-420.

ASLAN DEMIR, Sema (2013), Görünüş Kategorisi. Türkmence Örneği, Ankara: Grafiker Yayınları.

BACANLI, Eyüp (2006), "Türkçedeki Dolaylılık İşaretleyicilerinin Pragmatik Anlamları”, Modern Türklük Araştırmaları Dergisi, 3 (1): 35-47.

BACANLI, Eyüp (2008), “Türkiye Türkçesindeki -miş Ekinin Dolaylılık ve Dolaylılık-Dış1 Kullanımlarında Zamansal Atıf", Bilig, (44): 1-24.

BOZKURT, Fuat (1975), Untersuchungen zum Bojnurd-Dialekt des Chorasan türkischen, Göttingen.

CORNILLIE, Bert (2009), "Evidentiality And Epistemic Modality On The Close Relationship Between Two Diferent Categories", Functions Of Language, 16 (1): 44-62.

CSATÓ, Éva Agnes (2000), “Turkish mış- And ımış-Items. Dimensions Of A Functional Analysis”, Evidentials. Turkic, Iranian And Neighbouring Languages, (ed. Lars Johanson \& Bo Utas), Berlin \& New York: Mouton de Gruyte, 29-44.

DEMİR, Nurettin (2012), “Türkçede Evidensiyellik”, Bilig, (62): 97-118.

DEMİRCI, Kerim \& MÜHLBAUER, Jeff \& COOK, Clare (2010), “Delile Dayalılık Bakımından Türkiye Türkçesi ile Bazı Kızılderili Dillerinde Basit Çekimli Geçmiş Zamanlar", Turkish Studies, 5 (1): 281-293.

DOERFER, Gerhard (1998), “Turkic Languages Of Iran”, The Turkic Languages, (ed. Lars Johanson \& Éva Á. Csató), London \&New York: Routledge, 273-282.

DOĞAN, Talip (2016), Ġeşeng Ginle. Horasan Türkçesi Üzerine Bir Inceleme, Ankara: Akçağ Yayınları.

DOĞAN, Talip (2017a), Horasan Türkçesi Metinleri. Ireyimin Sézleri (Yüreğimin Sözleri). Giriş-NotlarMetin-Aktarma-Dizinler, Konya: Palet Yayınları.

DOĞAN, Talip (2017b), "Horasan Türkçesinin Bocnurd A ğzında \{-(I)ddI(r)\} ve \{-ūdi\} Yapıları", Modern Türklük Araştırmaları Dergisi, Haziran, 14 (2): 41-55.

FÁZSY, Szabolcs (1977), Das Bodschnurdi, ein türkischer Dialekt in Chorasan, Ostpersien, Zürich.

GÜL, Demet (2009), "Semantics Of Turkish Evidential -(I)mIş", Essay On Turkish Linguistics, (ed. Sila Ay etc.), 177-186.

HEYET, Cevat (2008), Türk Dilinin ve Lehçelerinin Tarihı̂ Seyri, (çev. Mürsel Öztürk), Ankara: TDK Yayınları.

JOHANSON, Lars (2000), "Turkic Indirectives", Evidentials. Turkic, Iranian And Neighbouring Languages, (ed. Lars Johanson \& Bo Utas), Berlin \& New York: Mouton de Gruyter, 61-87.

JOHANSON, Lars (2003), "Evidentiality In Turkic”, Studies In Evidentiality. Typological Studies In Language 54, (ed. Alexandra Y. Aikhenvald \& R. M. W. Dixon), Amsterdam \& Philadelphia: John Benjamins, 273-290.

Karşılaştırmalı Türk Lehçeleri Grameri I-Fiil-Basit Çekim (2006), (haz. Ahmet Bican Ercilasun, vd.), Ankara: TDK Yayınları.

KANAR, Mehmet (1997), Farsça. Dilbilgisi-Konuşma-Sözlük, İstanbul: Enderun Kitabevi.

KARADOĞAN, Ahmet (2009), Türkiye Türkçesinde Kılınış, Ankara: Divan Kitap.

KAZIMOV, Qezenfer Ş. (2010), Müasir Azerbaycan Dili. Morfologiya, Bakü: Elm ve Tehsil.

PALMER F. Robert (1986), Mood And Modality, Cambridge: Cambridge University Press.

PALMER, F. Robert (2001), Mood And Modality, Cambridge: Cambridge University Press.

PLUNGIAN, Vladimir A. (2010), "Types Of Verbal Evidentiality Marking: An Overview", Linguistic Realization Of Evidentiality In European Languages, (ed. Gabriele Diewald \& Elena Smirnova), Berlin \& New York: Walter de Gruyter, 15-58.

SCHROEDER, Christoph (2000), “Between Resultative, Historical And Inferential: Non-Finite -miş 
Forms In Turkish", Evidentials. Turkic, Iranian And Neighbouring Languages, (ed. Lars Johanson \& Bo Utas), Berlin \& New York: Mouton de Gruyter, 115.146.

TULU, Sultan (2009), Horasan Türklerinden Folklor Derlemeleri. Bocnurd Ağzı, Konya: Kömen Yayınları.

ÜZÜM, Melike (2017), Eski Anadolu Türkçesinde Epistemik Kiplik: Kısas-ı Enbiya Örneği, Hacettepe Üniversitesi Sosyal Bilimler Enstitüsü Türk Dili ve Edebiyatı Anabilim Dalı (Yayımlanmamış Doktora Tezi), Ankara.

WILLETT, Thomas (1988), "A Cross-Linguistic Survey Of The Grammaticization Of Evidentiality", Studies In Language 12, 51-97.

YILDIRIM, Nimet (2014), Farsça Dilbilgisi, İstanbul: Kabalcı Yayınları. 